\title{
Influência de diferentes taxas de crescimento de novilhas holandesas sobre a produção de leite e idade ao primeiro parto
}

\section{Influency of different Holstein heifers growth rates on milk production and age at first calving}

\author{
José Antônio de Freitas, ${ }^{*}$ Pedro H. N. Pinto, ${ }^{* *}$ Diogo Rodrigo Fronchetti, ${ }^{* *}$ Marcelo Falci Mota, ${ }^{*}$ \\ Rogério de Paula Lana, ${ }^{* * *}$ Júlio César de Souza*
}

\begin{abstract}
Resumo
A criação de novilhas tem contribuição relevante no custo total de produção de leite e as técnicas de manejo nela adotadas podem interferir na expressão dos parâmetros produtivos e reprodutivos do animal. Objetivou-se neste trabalho estabelecer relações entre taxa de ganho de peso de novilhas pré-púberes, idade ao primeiro parto e produção de leite na primeira lactação. Na primeira fase do estudo foram avaliados o crescimento de 84 fêmeas bovinas da raça Holandesa PO dos 6 aos 12 meses, pertencentes a duas propriedades. Na segunda fase, avaliou-se a idade ao parto e a produção de leite na $1^{\text {a }}$ lactação. Os animais foram pesados a cada 30 dias dos 6 aos 12 meses e registrou-se também a idade ao primeiro parto. Após o parto era feito o registro diário da produção de leite. De acordo com o ganho de peso dos 6 aos 12 meses os animais foram então alocados em três grupos (tratamentos): T1 ( $n=28)$ GMD menor que 0,70 kg/dia; T2 ( $n=28$ ) GMD entre 0,701 e $0,80 \mathrm{~kg} / \mathrm{dia}$ e T3 $(\mathrm{n}=28) \mathrm{GMD}$ superiores a $0,801 \mathrm{~kg} / \mathrm{dia}$. Dos seis meses ao parto o manejo adotado nas propriedades era semelhante. Entretanto, na fase de lactação os animais da fazenda 1 recebiam menor teor de concentrado na dieta total. Os dados foram submetidos à análise de variância, utilizando-se o programa estatístico SAS (2007) sendo as médias testadas pelo procedimento GLM do SAS. Não foi verificado efeito do ganho médio diário das novilhas sobre a produção de leite corrigido para 305 dias; entretanto, verificou-se efeito sobre idade ao primeiro parto. Devido ao manejo diferente adotado nas propriedades, na fase de lactação, e também à genética verificou-se efeito de fazenda sobre a produção de leite. O elevado desempenho animal durante a fase de recria pode ser responsável pela redução na idade ao primeiro parto sem, portanto, afetar a produção futura de leite.
\end{abstract}

Palavras-chave: desempenho produtivo, gado de leite, manejo nutricional, reprodução, taxa de crescimento, vacas leiteiras.

\begin{abstract}
The heifers raising has an important contribution in the total cost of milk production and management techniques adopted and can interfere with the expression of the productive and reproductive parameters of the animal. The objective of this work was to avaliate the correlations among the weight gain rate of heifers in pre-puberty, age at first birth and milk production in the first lactation. In the first phase of the study they were evaluated growth of 84 Holstein heifers from 6 to 12 months belonging to two farms. In the second phase, it was evaluated the age at first calving and milk production in the first lactation. The animals were weighed every 30 days from 6 to 12 months being registered the age at first calving. After the calving it was made the record of milk production daily. According to the weight gain from 6 to 12 months the animals were then allocated into three groups (treatments): T1 ( $n=28)$ - ADG of less than $0.70 \mathrm{~kg} /$ day; T2 $(n=28)-$ ADG between 0.701 and $0.80 \mathrm{~kg} /$ day and T3 ( $n=28)$ - ADG more than $0.801 \mathrm{~kg} /$ day. From six month age until the calving the management adopted was similar between farms; however in farm 1 the lactating animals received a smaller amount of concentrate in diet. The data were submitted to the analysis of variance, using the statistical program SAS (2007) and the means were tested by the GLM procedure of the SAS program. There was no effect of treatment on milk production corrected to 305 days; however, there was effect of treatment on age at first birth. Due to management adopted in different properties at the stage of lactation, and also due to the genetic there was effect of farm in milk production. The high animal performance during the growth phase may be responsible for reducing the age at birth without therefore affecting the future milk production compared with the moderate growth.
\end{abstract}

Keywords: growth rate, milking cattle, milking cows, nutritional management, productive performance, reproduction.

\footnotetext{
*Universidade Federal do Paraná - Campus Palotina, R. Pioneiro 2153, Dallas, Palotina PR, Brasil. CEP 85950-000

${ }^{* *}$ Mestrando em Ciências Veterinárias da Universidade Federal do Paraná.

***Graduando em Medicina Veterinária da Universidade Federal do Paraná. Bolsista Iniciação Científica PIBIC-CNPq.

${ }^{* * * * D Z O / U F V, ~ V i c ̧ o s a, ~ M G . ~ B o l s i s t a ~ d o ~ C N P q . ~}$
} 


\section{Introdução}

A criação de novilhas corresponde a um importante passo em sistema de produção de leite, sendo que o sucesso ou fracasso gerado nessa fase poderá refletir futuramente comprometendo significativamente a produção de leite. Tanto a super quanto a subalimentação pode refeletir negativamente na produção futura da novilha. Baixos níveis nutricionais determinam um atraso na vida reprodutiva e produtiva (Sartori, 2007; Miranda et al., 2003). Tais atrasos podem comprometer também a viabilidade econômica da atividade.

Os custos oriundos da criação de animais de reposição podem ser reduzidos por meio das reduções do tempo de criação e da quantidade de novilhas necessárias para manutenção da estabilidade do rebanho. Essa redução no tempo de criação das novilhas pode ser obtida, dentre outros fatores, por meio do aumento das taxas de crescimento corporal no período pré-pubertal, diminuindo assim as idades à puberdade, à primeira concepção e, consequentemente, ao parto, que segundo Sejrsen e Purup (1997), é a forma mais efetiva de redução destes custos e/ou no período póspubertal. Entretanto, Sejrsen e Purup (1997) elevadas taxas de ganho de peso no período pré-pubertal podem ter uma influência negativa no crescimento mamário de novilhas e na futura produção de leite. Ettema e Santos (2004) e Swanson (1960) sugerem que esta redução ocorre devido à formação anormal, no úbere, de algumas áreas destituídas de tecido secretor, ou seja, reduzido crescimento do parênquima mamário e concomitante aumento na deposição de tecido adiposo mamário. Tal fenômeno afetaria negativamente a produção de leite, uma vez que esta é estabelecida, primariamente, pelo número de células secretoras na glândula mamária (Knigth et al., 1984; Tucker, 1987).

Van Amburgh et al. (1998), ao formularem dietas que propiciaram ganhos de pesos de 0,68 a 0,94kg/dia, concluíram que apenas 2 a $8 \%$ da variação na produção de leite na primeira lactação foram justificados pelo ganho de peso diário.

Por outro lado, Radcliff et al. (1997), ao avaliarem taxas de crescimento de novilhas que variaram de 0,77 a 1,19kg/dia, não observaram diferenças quanto aos conteúdos de DNA e RNA parenquimáticos, ajustados ou não para o peso e quanto a relação RNA:DNA na glândula mamária. Durante o período de gestação, a alimentação também pode afetar o subsequente potencial de produção de leite de novilhas, uma vez que ela influencia o crescimento da glândula mamária, peso dos animais ao parto, tamanho e condição corporal, bem como o consumo de alimentos no pós-parto. Segundo Abeni et al. (2000), os resultados de pesquisa têm sido mais controversos ainda quanto ao efeito da nutrição sobre o crescimento durante o período entre a puberdade e o parto. Então, a afirmação de Ford e Park (2001), de que o sucesso dos programas de criação não deve ser medido apenas em termos de eficiência de crescimento corporal, mas também, em termos de potencial de produção de leite dos animais criados torna-se de grande relevância.

A restrição alimentar apresenta uma grande influência sobre a biologia e saúde dos animais de produção, tendo sido associada, em parte, às reduzidas taxas de crescimento das novilhas. Entretanto, embora a restrição alimentar excessiva possa causar, em animais em crescimento, a inibição do desenvolvimento normal da glândula mamária, regimes nutricionais bem-controlados em que se tem adotado a restrição energética, têm afetado positivamente 0 crescimento do parênquima mamário em novilhas leiteiras (Peri et al., 1993; Barash et al., 1994; Choi et al., 1997; Ford e Park, 2001).

Além de um ótimo plano de nutrição durante a recria, a raça e o potencial genético dentro da raça também afetam a produção de leite de vacas primíparas. A maioria dos estudos nos quais avaliou-se o efeito do manejo nutricional sobre o desenvolvimento da glândula mamária ou subsequente produção de leite de novilhas leiteiras tem sido desenvolvida com animais da raça holandesa (Choi et al., 1997; Radcliff et al., 1997; Abeni et al., 2000; Lammers e Heinrichs, 2000; Ford e Park, 2001).

Objetivou-se neste trabalho estabelecer relações entre taxa de ganho de peso de novilhas pré-púberes, idade ao primeiro parto e produção de leite na primeira lactação.

\section{Material e métodos}

A pesquisa foi realizada utilizando-se 84 fêmeas da raça holandesa, com idade média de seis meses e peso médio inicial de $232,5 \mathrm{~kg}$ sendo 30 pertencentes à fazenda 1 e 55 pertencentes à fazenda 2. A duração da pesquisa foi de aproximadamente 30 meses (envolvendo os animais dos 6 meses ao final da primeira lactação). Foram coletados dados referentes ao peso dos 6 aos 12 meses $(\mathrm{kg})$, idade ao primeiro parto e produção de leite na primeira lactação. Os animais foram agrupados nos tratamentos em função do ganho observado na fase compreendida entre 6 e 12 meses, da seguinte forma: T1 - Animais com ganho médio diário (GMD) menor que 0,70 kg/dia; T2 - GMD entre 0,701 e 0,80 $\mathrm{kg} /$ dia e T3 - GMD superiores a 0,801 kg/dia. Os animais foram submetidos aos manejos alimentar e sanitário semelhante do nascimento aos 6 meses de idade. No período compreendido entre 6 e 12 meses os animais foram mantidos em piquetes de gramíneas e suplementados com feno e concentrado em quantidades energéticas diferenciadas, dependendo do manejo alimentar adotado na propriedade. Após os 6 meses de idade, todas as novilhas eram mantidas em pastagem de Coast cross recebendo $2,0 \mathrm{~kg}$ de um concentrado com $18 \%$ de proteína e $75 \%$ de NDT composto de fubá de milho $(78,6 \%)$ e farelo de soja $(27,3 \%)$ além de $3 \%$ de mistura mineral comercial. Após o parto 0 manejo alimentar das vacas era diferenciado em função das propriedades, sendo que na fazenda 1 a dieta das vacas em lactação nas duas propriedades foi balanceada de acordo com as exigências nutricionais do NRC (2001).

Após o parto, os animais da fazenda 1 receberam aproximadamente $60 \%$ das exigências nutricionais (NRC, 2001) no cocho após cada ordenha (manhã e tarde). O alimento fornecido no cocho era composto de silagem de milho e concentrado comercial contendo $18 \%$ de proteína bruta e $75 \%$ de NDT. Após as ordenhas, as vacas eram soltas em pastagens de capim brachiaria brizantha. A suplementação mineral era feita diretamente no concentrado.

$\mathrm{Na}$ fazenda 2, as vacas recebiam, no pós-parto, ração balanceada, na forma de ração total contendo $20 \%$ de proteína bruta e eram mantidas durante todo o dia em regime de confinamento. Com relação ao teor de proteína da ração 
total, vale salientar que tais teores são superiores aos recomendados pelo NRC (2001).

Os animais eram ordenhados mecanicamente, duas vezes ao dia, sendo que os registros de produção eram computados diariamente. As análises estatísticas serão realizadas pelo pacote estatístico SAS (2007) de acordo com o procedimento linear geral (GLM), para análise de variância e teste de comparação múltipla de médias ao nível de $5 \%$ de significância.

\section{Resultados e discussão}

Não foi verificado efeito $(P>0,01)$ do tratamento sobre a produção de leite $(\mathrm{kg})$ corrigido para 305 dias; entretanto, verificou-se $(P<0,01)$ efeito do tratamento sobre idade ao primeiro parto (Tabela 1).

Tabela 1: Médias da produção de leite corrigida para 305 dias de lactação e idade ao primeiro parto (meses) e seus respectivos erros-padrões, em função dos tratamentos para vacas Holandesas PO mantidas confinamento

\begin{tabular}{ccccc}
\hline Tratamento & $\begin{array}{c}\text { Produção média } \\
(\mathrm{kg})\end{array}$ & Erro-padrão & $\begin{array}{c}\text { Idade ao } 1^{\circ} \text { parto } \\
\text { (meses) }\end{array}$ & Erro-padrão \\
\hline 01 & $7014 \mathrm{a}$ & 218,68 & $27,6 \mathrm{a}$ & 0,6 \\
02 & $6873 \mathrm{a}$ & 384,42 & $28,7 \mathrm{a}$ & 1,1 \\
03 & $7224 \mathrm{a}$ & 354,18 & $25,0 \mathrm{~b}$ & 1,0 \\
\hline
\end{tabular}

*Médias seguidas pela mesma letra na mesma coluna não diferiram estatisticamente pelo teste $\mathrm{F}$ ao nível de $5 \%$ de probabilidade.

Conforme observados na Tabela 1, os dados encontrados são discordantes dos apresentados pela literatura na qual se estabelece que ganhos médios diários acima de $0,75 \mathrm{~kg} /$ dia poderiam trazer prejuízo à produção futura destes animais (NRC, 2001). Resultados discordantes foram verificados por Meyer et al. 2006 e Davis et al., 2009 os quais observaram menores quantidades de DNA na glândula mamária de novilhas leiteiras submetidas a um elevado plano nutricional.

Segundo Zanthon e Heinrichs (2005), apesar de haver decréscimo no desenvolvimento da glândula mamária em animais pré-púberes que apresentem elevados ganhos de peso, as respostas relacionadas com a produção de leite na primeira lactação e o ganho de peso na fase pré-pubertal são inconsistentes. Entretanto, os autores verificaram resposta quadrática da produção de leite (corrigida para 305 dias) em função do ganho de peso, sendo a maior produção de leite verificada com níveis de ganho de peso próximo de $0,8 \mathrm{~kg} /$ animal/dia.

Da mesma forma, Santos et al. (2002) relataram que ganhos médios diários acima de $0,78 \mathrm{~g} / \mathrm{dia}$, antes e depois da puberdade, reduzem a produção de leite em até $20 \%$. O fato de os animais do tratamento 3 da presente pesquisa não apresentarem prejuízo na produção de leite pode estar relacionado com a maior estrutura física destes, o que possibilitou aos mesmos ganharem maior peso, sem favorecer a deposição de gordura na glândula mamária. A maior produção de leite, verificada nestes animais, provavelmente ao maior peso destes o que proporcionaria maior consumo de matéria seca e, consequentemente, maior produção de leite. Tal resultado está de acordo com Carson et al. (2000) os quais verificaram que novilhas holandesas de alto mérito genético são menos sensíveis a dietas ricas em energia podendo, deste modo, suportar um ganho de até $0,950 \mathrm{~kg} /$ dia sem prejudicar sua futura produção leiteira.

De acordo com a literatura (Zanton e Heinrichs, 2009) ganhos de peso acima do recomendado pela literatura, para novilhas, pode ser benéfico no sentido de se reduzir a idade à primeira cria. Essa teoria foi confirmada no presente estudo, onde se verificou que maiores taxas de ganho de peso, no tratamento 3 , na fase pré-pubertal proporcionaram menores idades ao primeiro parto, não havendo diferenças entre os ganhos intermediáiros (T2) e baixo (T1. O valor médio obtido no tratamento 3 foi inferior ao verificado por Heinrichs et al. (1994), para a raça holandesa.

A menor idade ao primeiro parto no tratamento 3 pode estar relacionada com a correlação idade e peso. Deste modo, animais que apresentassem um maior ganho de peso na fase de recria atingiria o peso à puber-dade em idade inferior e teriam possibilidade de parir mais precocemente (NRC, 2001). O fato de não ter sido observada diferença $(P>0,01)$ entre os tratamentos 1 e 2 pode estar associado ao ganho compensatório dos animais do tratamento 1 , uma vez que o manejo alimentar dos animais depois dos 12 meses era o mesmo. Segundo Heinrichs e Lammers (1998), o crescimento compensatório pode fazer com que novilhas alimentadas com dietas pobres podem atingir a puberdade em tempo apropriado (13-15 meses).

Os resultados verificados no presente estudo são concordantes com os resultados verificados por Sejrsen e Purup (1997) os quais verificaram que aumento na taxa de ganho de novilhas de 450 para 850 gramas por dia foi suficiente para reduzir a idade ao primeiro cio de 16,6 para 8,4 meses. A taxa de ganho de peso verificada pelos autores que resultou em redução na idade ao primeiro cio, se encontra dentro do intervalo $(0,8-1,0 \mathrm{~kg} / \mathrm{dia})$ onde foram obtidas as menores idades ao primeiro parto, na presente pesquisa. Resultados semelhantes foram observados por Van Amburgh et al. (1998), ao formularem dietas que propiciaram ganhos de pesos de 0,68 a 0,94 kg/dia, onde verificaram que houve pouca variação na produção de leite na primeira lactação em função do peso ganho por novilhas. Outro fator importante com relação à criação de novilhas leiteiras é o fato de que animais que dão cria mais cedo apresentam maior produção por vida útil no rebanho.

De forma semelhnate, foram obtidos por Radcliff et al. (1997), ao avaliarem taxas de crescimento de novilhas que variaram de 0,77 a $1,19 \mathrm{~kg} /$ dia, e não observaram diferenças quanto aos conteúdos de DNA e RNA parenquimáticos, na glândula mamária. Tal fato indica que maiores taxas de ganho de peso das novilhas seriam de grande interesse por reduzir a idade ao primeiro parto. Por outro lado, resltados discordantes foram obtidos por Meyer et al. (2006) e Davis et al. (2009) os quais verificaram menores quantidades de DNA na glândula mamária de novilhas leiteiras submetidas a um elevado plano nutricional. 
Com relação ao efeito de Fazenda, verificou-se na pesquisa efeito significativo associado à fazenda $(P<0,01)$ sobre a produção de leite (Tabela 2 ). Este fato pode estar associado ao melhor manejo nutricional adotado na fazenda 1 durante a fase de lactação. Entretanto, não se verificou $(P>0,05)$

Tabela 2: Médias da produção de leite corrigida para 305 dias (kg), idade ao primeiro parto (meses) e seus respectivos erros-padrões, em função de fazenda

\begin{tabular}{ccccc}
\hline Fazenda & $\begin{array}{c}\text { Produção média } \\
(\mathrm{kg})\end{array}$ & Erro-padrão & $\begin{array}{c}\text { Idade ao 10 parto } \\
(\mathrm{m})\end{array}$ & Erro-padrão \\
\hline 1 & $5659,97 \mathrm{a}$ & 302,27 & $26,58 \mathrm{a}$ & 0.85 \\
2 & $8814,78 \mathrm{~b}$ & 216,46 & $27,62 \mathrm{a}$ & 0,61 \\
\hline
\end{tabular}

*Médias seguidas pela mesma letra na mesma coluna não diferem estatisticamente a $1 \%$ de probabilidade pelo procedimento GLM do SAS. diferença no que se refere à idade ao primeiro parto das novilhas, entre propriedade. Tal fato pode estar associado às menores diferenças no manejo alimentar das novilhas nas duas fazendas.

\section{Conclusões}

O desempenho animal durante a fase de recria pode ser responsável pela redução na idade ao primeiro parto sem, portanto, afetar a produção futura de leite.

Taxas de ganho de peso acima de $0,8 \mathrm{~kg}$ não são prejudiciais no que diz respeito à produção de leite; porém, são eficientes em reduzir a idade ao primeiro parto, embora mais trabalhos devam ser feitos, pois o assunto ainda tem-se mostrado contraditório.

\section{Referências}

ABENI, F.; CALAMARI, L.; STEFANINI, L. et al. Effects of daily gain in pre and postpubertal replacement dairy heifers on body condition score, body size, metabolic profile, and future milk production. Journal of Dairy Science, v. 83, p. 1468-1478, 2000.

BARASH, H.; BAR-MEIR, Y.; BRUCKENTAL, I. Effects of low-energy diet followed by a compensatory diet on growth, puberty and milk production in dairy heifers. Livestock Production Science, v. 39, p. 263-268, 1994.

BETHARD, G.L. A microcomputer simulation to evaluate management strategies for rearing dairy replacements. Ph.D. Dissertation. Faculty of the Virginia Polytechnic Institute and State University, BlacksburgVirginia, USA, 1997.

CARSON, A.F.; WYLIE, A.R.G.; MCEVOY, J.D.G. et al. Effects of plane of nutrition and diet type on mammogenic hormone concentrations, growth and milk production in high genetic merit dairy herd replacements. Animal Science, v. 70, p. 349-362, 2000.

CHOI, Y.J.; HAN, K.I.; WOO, H.J. et al. Compensatory growth in dairy heifers: The effect of a compensatory growth pattern on growth rate in lactation performance. Journal of Dairy Science, v. 80, p. 519524, 1997.

FORD, A.J.; PARK, C.S. Nutritionally directed compensatory growth enhances heifer development and lactation potential. Journal of Dairy Science, v. 84, p. 1669-1678, 2001.

HEINRICHS, A.J.; WELLS, A.J.; HURD, H.S. etal. The national dairy heifer evaluation project: a profile of heifer management practices in the United States. Journal of Dairy Science, v. 77, n. 6, p. 1548-1555, 1994.

HEINRICHS, J.; LAMMERS, B. Monitoring dairy heifer growth. Tecnichal Bulletin. The Pennsylvania State University. 1998. Disponível no site. http://www.das.psu.edu/user/publications/pdf/ud006.pdf. Consultado dia 8 de setembro de 2008.

KNIGHT, C.H.; DOCHERTY, A.H.; PEAKER, M. Milk yield in rats in relation to activity and size of mammary secretory cell population. Journal of Dairy Research, v. 51, p. 29-35, 1984.

LABARCA, A.; PAIGEN, K. A simple, rapid and sensitive DNA assay procedure. Analitical Biochemistry, v. 102, p. 344-352, 1980.

LAMMERS, B.P.; HEINRICHS, A.J. The response of altering the ratio of dietary protein to energy on growth, feed efficiency, and mammary development in rapidly growing prepubertal heifers. Journal of Dairy Science, v. 83, p. 977-983, 2000.

LOWRY, O.H.; ROSEBROUGH, N.J.; FARR, A.L. et al. Protein measurement with the folin phenol reagent. Journal of Biological Chemistry, v. 193, p. 265-272, 1951.
MIRANDA, J.E.C.; RIBEIRO, A.C.C.L.; CAMPOS, O.F. et al. Cria e recria de fêmeas leiteiras: passo a passo. Juiz de Fora: Embrapa Gado de Leite, 2003. p. 6. (Comunicado Técnico, 30).

NATIONAL RESEARCH COUNCIL (NRC). Nutrient requeriments of dairy cattle. $7^{\mathrm{a}}$ ed. Washington, D.C.: National Academy Press, 2001. 381p. PERI, I.; GERTLER, A.; BRUCKENTAL, I. et al. The effect of manipulation of energy allowance during the rearing period of heifers on hormone concentrations and milk production in first lactation cows. Journal of Dairy Science, v. 76, p. 742-751, 1993.

RADCLIFF, R.P.; VANDEHAAR, M.J.; SKIDMORE, A.L. et al. Effects of diet and bovine somatotropin on heifer growth and mammary development. Jounal of Dairy Science, v. 80, p. 1996-2003, 1997.

SARTORI, R. Manejo reprodutivo da fêmea leiteira. Revista Brasileira de Reprodução Animal, v. 31, n. 2, p. 153-159, 2007.

SANTOS, G.T.; DAMASCENO, J.C.; MASSUDA, E.M. et al. Importância do manejo e considerações econômicas na criação de bezerras e novilhas. In: Anais do II Sul-Leite: Simpósio sobre Sustentabilidade da Pecuária Leiteira na Região Sul do Brasil 2002, Toledo-PR. 212 p.

SAS Institute Inc. Statistical Analysis System Introductory Guide for Personal Computers. Release. Cary, NC: SAS Institute Inc. 2007.

SEJRSEN, K.; PURUP, S. Influence of prepubertal feeding level on milk yield potential of dairy heifers: a Review. Journal of Animal Science, Champaign, v. 75, n. 3, p. 828-835, 1997.

SWANSON, E.W. Effect of rapid growth with fattening of dairy heifers on their lactational ability. Journal of Dairy Science, v. 43, p. 377-387, 1960.

TUCKER, H.A. Quantitative estimates of mammary growth during various physiological states: A review. Journal of Dairy Science, v. 70, p. 1958-1966, 1987.

VAN AMBURGH, M.E.; GALTON, D.M.; BAUMAN, D.E. et al. Effects of three prepubertal body growth rates on performance of Holstein heifers during first lactation. Journal of Dairy Science, v. 81, p. 527538, 1998.

ZANTON, G.I.E.; HEINRICHS, A.J. Meta-analysis to assess effect of prepubertal average daily gain of holstein heifers on first-lactation production. Jounal of Dairy Science, v. 88, p. 3860-3867, 2005.

ZANTON, G. I. AND HEINRICHS, G. I. Limit-Feeding with altered Forageto-Concentrate Levels in Dairy Heifer Diets. A Review. The Professional Animal Scientist n. 25, p. 393-403. 2009. 